\title{
Liquid Chromatography Mass Spectrometer (Lc/Ms) Profile Revealed Flavonoids And Terpenoids With Antioxidant Potential In Aqueous Fraction Of Combretum Micranthum Leaf Extract
}

\author{
Aminu Ibrahim ${ }^{1}$ and Musa Bashir ${ }^{2 *}$ \\ ${ }^{1}$ Department of Biochemistry, \\ Faculty of Basic Medical Sciences, \\ Bayero University, Kano-Nigeria. \\ ${ }^{2}$ Centre for Dryland Agriculture, \\ Bayero University, \\ Kano-Nigeria. \\ Email: mbashir.cda@buk.edu.ng
}

\begin{abstract}
Combretum micranthum (CM) is commonly used for its ethno-medicinal potentials without much or no scientific basis. Thus, the aim of this research is to evaluate aqueous fraction of C. micranthum leaf extract for possible antioxidant compounds using liquid chromatography mass spectrometer technique. In vitro antioxidant was carried out using 2,2-diphenyl-1-picrylhydrazyl (DPPH) and Ferric Reducing Power (FRAP) assay methods and the results indicated the free radical scavenging activity of $80.351 \pm 0.732$ and $0.800 \pm 0.00$ at $2.50 \mathrm{mg} / \mathrm{m} 1$ concentrations which is significantly different when compared to reference standard of $84.718 \pm 0.605$ and $0.426 \pm 0.000$ (ascorbic acid) respectively, with concentration or dose-dependent. LC-MS profile revealed the presence of medicinally important compounds like Myricetin (Flavone), Epioxylubimin (Sesquiterpenoids), Furocoumaric acid (Phenolic glycoside) among others. The findings of this study revealed that $C$. micranthum is rich in potential metabolites and was reflected as its antioxidant potential and could be used for drug and other oxidative stress related management.
\end{abstract}

Key Word: Combretum micranthum, Antioxidant, Metabolite, LCMS

\section{INTRODUCTION}

Combretum micranthum, (CM), Combretaceae is an undomesticated shrub species majorly found in western part of Africa and is one of the most used traditional bush teas most especially in Senegal. Traditionally the herbal beverage is used for weight loss, digestion, mild antibiotic, and for other pharmacological benefit. Combretum micranthum, specifically used as a general panacea that the name kinkéliba has become a word synonymous with "medicine" in some languages (Eloff, et al., 2008). The use of natural resources emerging in general as one of the most important and suitable means to explore in the search for new and more effective antibacterial

*Author for Correspondence

A. Ibrahim, M. Bashir, DUJOPAS 7 (4b): 150-159, 2021 
drugs and particularly medicinal plants (Yoda et al., 2020). Recently many literature revealed the presence of important bioactive metabolites with many biological activities (Yoda et al., 2020). The survey on phytochemical and biological activity of C. micranthum has re-confirmed the presence of these metabolites. Hydroalcoholic extract of C. micranthum (CM extract) showed a strong antioxidant activity by scavenging $\mathrm{AAPH}, \mathrm{DPPH}$, nitric oxide, hydrogen commonly used for pharmaceutical benefit throughout West Africa. (Kpemissi et al., 2019).

Additionally, C. micranthum was mentioned as one of the 50 most important African medicinal plants by Association for African Medicinal Plant Standards. Burkhill (1985) has reported many benefits of species found in combretaceae including, but not limited to, anthelminthic, colitis, constipation, diuretic, expectorant, gingivitis, guinea worm, parasites, malaria, nausea, purgative, thrush, tuberculosis and yellow fever. It is clear, from this report that Combretaceae species play an important part in Africa's traditional medicines.

Modern scientific research indicates that leaf extracts exhibit a number of pharmacological activities. For example, a kinkeliba decoction was shown to inhibit both strains of Plasmodium falciparum in vitro (chloroquine-sensitive and chloroquine-resistant), indicating its uses for the treatment of malaria infection (Benoit et al., 1996). In many literatures this plant was reported to be medicinally important most especially for antimicrobial and anti-inflammatory activities against both strains of bacteria (Olajide et al., 2003; Udoh et al., 2012). Therefore continuous research to investigate the bark, roots and branches of the plant, may lead to elucidate, develop the mode of therapeutic action that is utilized in the tea and ultimately employed in foods, beverages and, if therapeutically valid, it can be useful in modern health care or medicine.

In a normal cellular condition the ratio between appropriate oxidant and antioxidant is balanced. However, any shift of this balance may cause the increased production of oxygen species or decreased antioxidant level and consequently causes oxidative stress. Similarly this would result in damaging the biopolymers such as nucleic acids, proteins, poly-unsaturated fatty acids and carbohydrates. It also causes serious cell damage leading to a variety of health conditions such as Alzheimer's disease, Parkinson's disease, atherosclerosis, cancer, arthritis, immunological incompetence and neurodegenerative disorders among others. Many literatures reported that plant extracts is rich in phenol acids exhibit strong antioxidant and antiradical poentilas in vitro (Mary et al., 2003) and in vivo (Rajlakshmi et al., 2003). However, the use of synthetic antioxidants have been restricted due to their health risks and toxicity (Linderschmidt et al., 1986). The need to evaluate or identify phytochemical from natural sources with antioxidant potential or with pharmacological benefit will not be overemphasis. Therefore this study is aimed to determine the antioxidant potential of C. micranthum aqueous fraction and identify the possible metabolites responsible using LCMS technique.

\section{MATERIALS AND METHODS}

Chemical/Reagent. All chemicals and reagents used are of analytical grade and purchased from sigma Aldrich.

\section{Sample Collection and Extraction}

The leaves of $C$. micranthum were collected from Filin Shagari Area, Bauchi State, Nigeria. It was taken to herbarium unit of biological science department, Bayero University Kano for identification and voucher specimen no. BUKHAN0349 was deposited. The leaves were shade 
dried and ground into powder using a clean metal mortar and pestle and were extracted using maceration method (Ibrahim et al. (2017).

\section{DPPH Assay}

This assay was carried out as described by Shen et al. (2010) with slight modification. About $0.1 \mathrm{mM}$ solution of DPPH in methanol was prepared and $2 \mathrm{~cm}^{3}$ of this solution was added to $1 \mathrm{~cm}^{3}$ of various concentration of the extract fraction $(0.16,0.3125,0.62,1.25$ and 2.50 $\mathrm{mg} / \mathrm{cm}^{3}$ ). The mixtures were shaken vigorously and incubated at room temperature for 30 minutes. Methanol was used as a blank and DPPH in methanol without the plant extract was used as positive control. Then the absorbance was measured at $517 \mathrm{~nm}$ using a UV-VIS Spectrophotometer. Ascorbic acid was used as the reference. The capability of scavenging the DPPH radical was calculated by using the following formula; DPPH scavenging effect (\% inhibition $\left.)=\{(\mathrm{A} 0-\mathrm{A} 1) / \mathrm{A} 0)^{*} 100\right\}$.

Where, A0 is the absorbance of the control reaction, and A1 is the absorbance in presence of all of the extract samples and reference. All the tests were performed in triplicate. The $\mathrm{IC}_{50} \mathrm{value}$ was determine as the half-maximum concentration of the extract (in $\mathrm{mg} / \mathrm{mL}$ ) that scavenge $50 \%$ of DPPH.

\section{Ferric Reducing Power Assay}

The reducing power of aqueous fraction C. micranthum was measured using the method described by Ferreira et al. (2007) with slight modification. About $2.5 \mathrm{~cm}^{3}$ of extracts fractions at different concentrations $\left(0.1625,0.625,0.3125,1.251 .25\right.$ and $\left.2.50 \mathrm{mg} / \mathrm{cm}^{3}\right)$ were mixed with 2.5 $\mathrm{cm}^{3}$ phosphate buffer $(0.2 \mathrm{M}, \mathrm{pH} 6.6)$ and $2.5 \mathrm{~cm}^{3}$ of $1 \%$ potassium ferricyanide. The mixtures were incubated at $50^{\circ} \mathrm{C}$ for 20 minute, and allowed to cooled, mixed with $2.5 \mathrm{ml}$ of $10 \%$ trichloroactic acid and centrifuged at $6500 \mathrm{rpm}$ for 10 minute. The supernatant $\left(2.5 \mathrm{~cm}^{3}\right)$ for each were mixed with distilled water $\left(2.5 \mathrm{~cm}^{3}\right)$ and ferric chloride $\left(0.5 \mathrm{~cm}^{3}, 0.1 \%\right)$ then finally allowed

to stand for $10 \mathrm{~min}$. The absorbance was read at $700 \mathrm{~nm}$ using UV-Vis spectrometer. Ascorbic acid was used as standard against reagent in distilled water as blank.

\section{Liquid Chromatography Mass Spectrometer (LC-MS) Analysis}

The LCMS profile was carried out according to the method (Piovesana et al. (2018) with some modifications. The extract samples were dissolved in Methanol and filtered through polytetrafluoroethylene (PTFE) membrane filter with $0.45 \mu \mathrm{m}$ size. Then, the filtrate $(10.0 \mu \mathrm{l})$ was injected into the LC system and allowed to separate on Sunfire C18 $(5.0 \mu \mathrm{m} 4.6 \mathrm{~mm} \times 150$ $\mathrm{mm}$ ) Column. The run was carried out at a flow rate of $1.0 \mathrm{~mL} / \mathrm{min}$, Sample and Column temperature at $25^{\circ} \mathrm{C}$. The mobile phase consists of solvent $\mathrm{A}(0.1 \%$ formic acid in water $)$ and solvent B (0.1\% formic acid in Acetonitrile) with a gradient as shown in table 1. 
Table 1: Liquid Chromatography Mass Spectrometer (LC-MS) Solvent gradient (\%)

\begin{tabular}{lll}
\hline Time & \%A & \% B \\
\hline $\mathbf{0}$ & 95 & 5 \\
$\mathbf{1}$ & 95 & 5 \\
$\mathbf{1 3}$ & 5 & 95 \\
$\mathbf{1 5}$ & 5 & 95 \\
$\mathbf{1 7}$ & 95 & 5 \\
$\mathbf{1 9}$ & 95 & 5 \\
$\mathbf{2 0}$ & 95 & 5
\end{tabular}

NOTE: Solvent A ( $0.1 \%$ formic acid in water), Solvent B (0.1\% formic acid in Acetonitrile) A ratio of A/B 95:5 was used from the beginning and hold for further $1 \mathrm{~min}$, then A/B 5:95 for $13 \mathrm{~min}$ and hold to $15 \mathrm{~min}$. then A/B $95: 5$ to $17 \mathrm{~min}, 19 \mathrm{~min}$ and finally $20 \mathrm{~min}$. the PDA detector was set at $210-400 \mathrm{~nm}$ with resolution of $1.2 \mathrm{~nm}$ and sampling rate at 10 points/sec. The mass spectra were acquired with a scan range from m/z 100 - 1250 after ensuring the following settings: ESI source in positive and negative ion modes; capillary voltage $0.8 \mathrm{kv}$ (positive) and $0.8 \mathrm{kv}$ (negative); probe temperature $600^{\circ} \mathrm{C}$; flow rate $10 \mathrm{~mL} / \mathrm{min}$; nebulizer gas, 45 psi. MS set in automatic mode applying fragmentation voltage of $125 \mathrm{~V}$. The data was processed with Empower 3. The compounds were identified on the basis of the following information, elution order, and retention time (Rt), fragmentation pattern, and Base $\mathrm{m} / \mathrm{z}$.

\section{Statistical Analysis}

Data were analyzed using SPSS Minitab package. ANOVA was used to identify the cause of differences. The results were expressed as mean \pm standard deviation (SD) of triplicates determination and $\mathrm{IC}_{50}$ for percentage inhibition was calculate.

\section{RESULTS}

DPPH and FRAP Radical Scavenging Activities of Combretum micranthum Leaf Extract in aqueous Fraction.

In vitro antioxidant studies were carried out using DPPH and Ferric Reducing Power (FRAP) assay methods as presented in Table 2 and 3 respectively. The findings revealed the free radical scavenging activity of $80.351 \pm 0.732$ and $0.800 \pm 0.00$ at $2.50 \mathrm{mg} / \mathrm{m} 1$ concentrations which is significantly different when compared to reference standard of $84.718 \pm 0.605$ and $0.426 \pm 0.000$ (ascorbic acid) respectively. And concentration or dose-dependent, with IC50 1.491 \pm 0.716 .

\section{Liquid Chromatography Mass Spectrometer (LC-MS) Analysis}

The LCMS profile of aqueous fraction of C. micranthum leaf was conducted as presented in Table 4 . However the results revealed the presence of many medicinally important compounds like Myricetin (Flavone), Epioxylubimin (Sesquiterpenoids), and Furocoumaric acid (Phenolic glycoside) among others at positive mode, which tentatively identified using data base by comparing their molecular fragmentations pattern. 
TABLE 2: DPPH scavenging activity of $C$. micranthum leaf extract aqueous fractions using ascorbic acid as standard.

Results are expressed in mean \pm standard deviation

\begin{tabular}{ccc}
$\begin{array}{c}\text { Concentration of the } \\
\text { extract }(\mathbf{M g} / \mathbf{m l}) .\end{array}$ & $\begin{array}{c}\text { Antioxidant inhibition } \\
\mathbf{( \% )}\end{array}$ & $\begin{array}{c}\text { Antioxidant inhibition } \\
\mathbf{( \% )}\end{array}$ \\
\hline & Ascorbic acid & Aqueous \\
$\mathbf{2 . 5}$ & $84.718 \pm 0.605$ & $80.351 \pm 0.732$ \\
$\mathbf{1 . 2 5}$ & $82.481 \pm 1.359$ & $80.032 \pm 0.889$ \\
$\mathbf{0 . 6 2 5}$ & $80.405 \pm 2.567$ & $78.594 \pm 1.365$ \\
$\mathbf{0 . 3 1 2 5}$ & $78.754 \pm 3.503$ & $76.358 \pm 0.319$ \\
$\mathbf{0 . 1 5 6 2 5}$ & $69.861 \pm 14.279$ & $68.424 \pm 2.272$ \\
$\mathbf{I C} \mathbf{5 0}$ & $1.438 \pm 0.688$ & $1.491 \pm 0.716$ \\
\hline
\end{tabular}

TABLE 3: FRAP scavenging activity of $C$. micranthum leaf extract aqueous fractions using ascorbic acid as standard.

Concentration of the extract

$(\mathrm{Mg} / \mathrm{ml})$.

Antioxidant inhibition (\%)

Ascorbic acid

$0.426 \pm 0.000$

$0.425 \pm 0.001$

$0.364 \pm 0.045$

$0.281 \pm 0.001$

$0.167 \pm 0.001$
Antioxidant inhibition (\%)

\section{Aqueous}

$0.800 \pm 0.002$

$0.359 \pm 0.001$

$0.351 \pm 0.001$

$0.313 \pm 0.001$

$0.204 \pm 0.001$

Results are expressed in mean \pm standard deviation

TABLE 4: LC-MS analysis of aqueous fraction of leaf extract of C. micranthum.

\begin{tabular}{lccc}
\hline PEAK & COMPOUNDS NAME & MW & M/Z \\
\hline $\mathbf{1}$ & Furocoumarinic acid (phenolic & 366 & 367.809 \\
$\mathbf{2}$ & $\begin{array}{c}\text { glycoside) } \\
\text { 12-tricosanol }\end{array}$ & 340 & 341.666 \\
$\mathbf{3}$ & Fenarimol & 331 & 332.132 \\
$\mathbf{4}$ & Myricetin (Flavonol) & 318 & 319.062 \\
$\mathbf{5}$ & Epioxylubimin (sesquiterpenoid) & 269 & 270.268
\end{tabular}

MZ - Mass to charge ratio, MW - Molecular Weight 




Figure 1: Total chromatogram of aqueous fraction of C. micranthum leaf

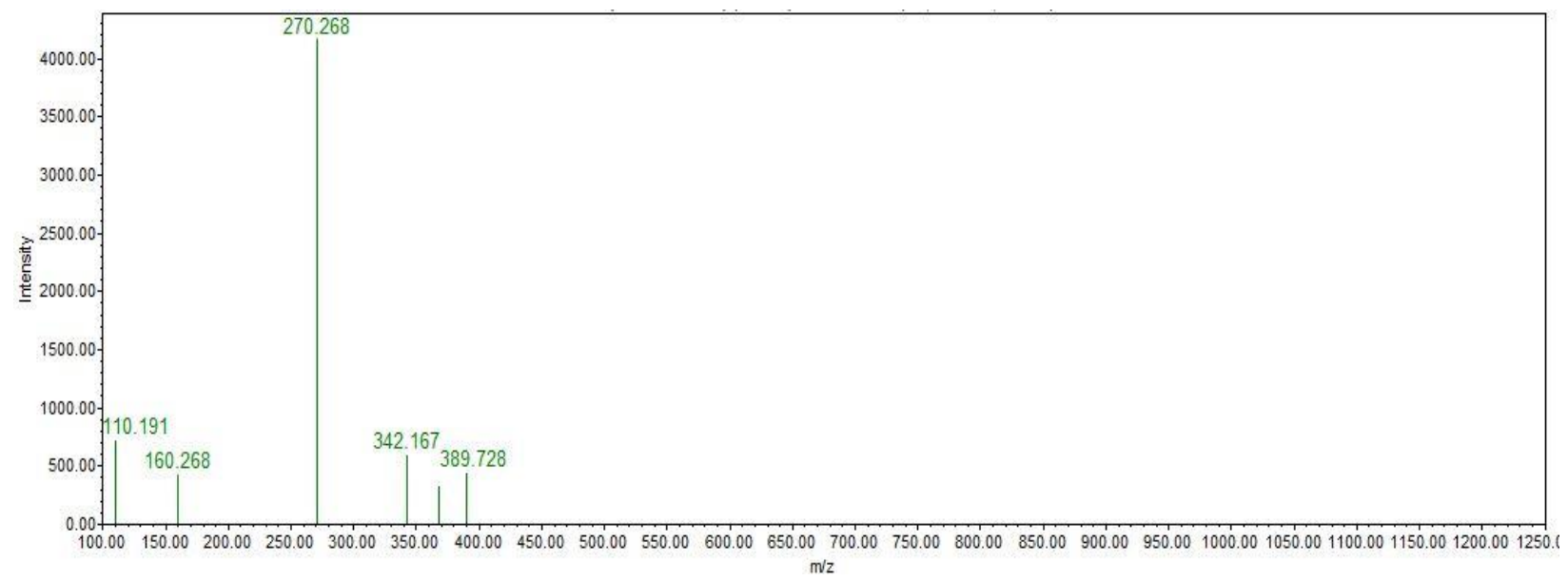

Figure 2: Molecular fragmentation of Epioxylubimin (Sesquiterpenoid) $270.268 \mathrm{~m} / \mathrm{z}$

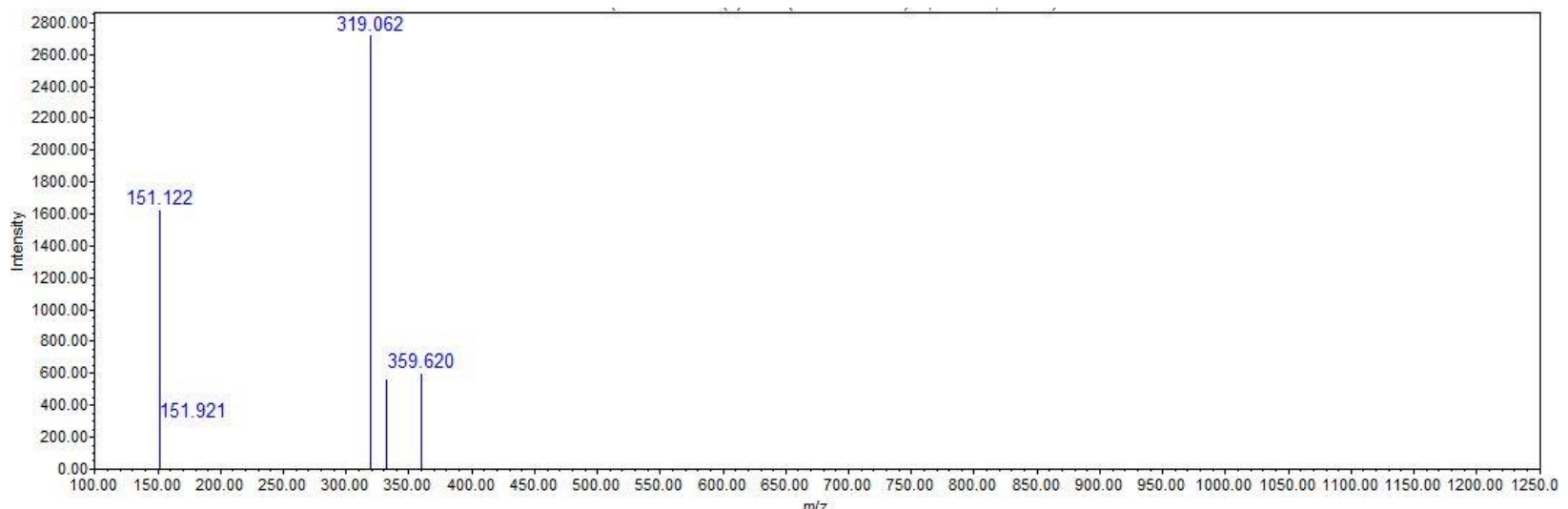

Figure 3 Molecular fragmentation of Myricetin (flavonol) $319.062 \mathrm{~m} / \mathrm{z}$ 


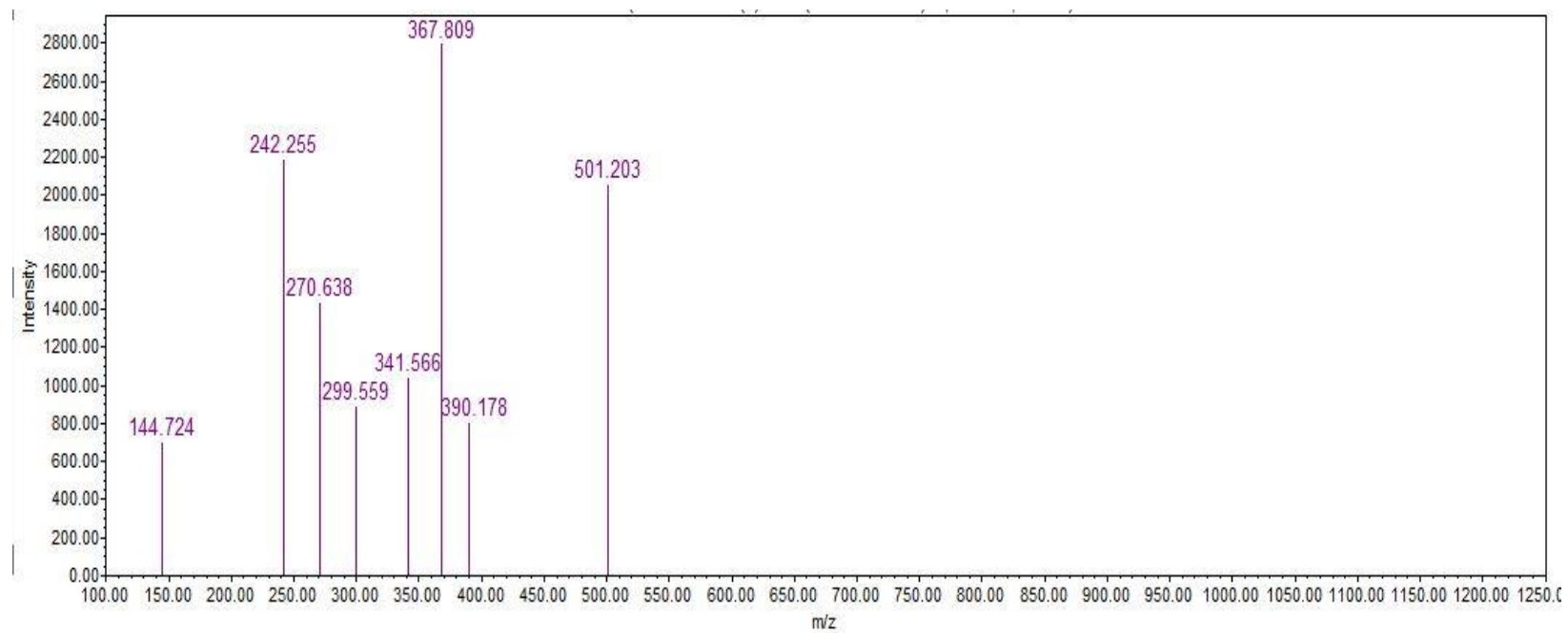

Figure 4: Molecular fragmentation of Furocoumarinic acid (phenolic glycoside) $367.809 \mathrm{~m} / \mathrm{z}$

\section{DISCUSSION}

In the present study, aqueous leaf extract of C. micranthum exhibited DPPH radical scavenging activity of $80.351 \pm 0.732$ at $2.5 \mathrm{mg} / \mathrm{ml}$ concentration which is significantly different with reference standard of $84.718 \pm 0.605$ (Ascorbic acid), and concentration or dose-dependent. The antioxidant capacity was also expressed as $50 \%$ inhibitory concentration $\left(\mathrm{IC}_{50}\right)$ and it shows a value of $1.491 \pm 0.716$, however the ascorbic acid used as a reference standard has higher antioxidant potential than the extract used with $\mathrm{IC}_{50}$ value of $1.039 \pm 0.006$. Similarly, for the FRAP, the result indicated that aqueous leaf extract of $C$. micranthum revealed appreciable antioxidant activity with $0.800 \pm 0.00$ at $2.5 \mathrm{mg} / \mathrm{ml}$ of the extract as compared to $0.426 \pm 0.000$ for ascorbic acid as reference standard, however the results shows concentration or dosedependency.

Previous studies revealed there was positive and potential effect on cardiac performance as a results of flavonoid intake (Banjarnahor and Artanti 2014). Recently, in vivo studies conducted by Liu, et al. (2014) using experimental rat found that production of antioxidant enzyme activity increases by quercetin consumption, such as glutathione-peroxidase (GSH-Px), glutathione reductase (GR), superoxide dismutase (SOD), and catalase (CAT), similarly it helps to preserve membrane integrity and subsequently prevents lipid peroxidation. Therefore based on these findings, the extract could be a good supplement that will help in prevention of lipid peroxidation or oxidative stress and subsequently organ damage.

The result of the LC-MS analyses aqueous leaf extract of $C$. micranthum revealed the presence of medicinally important compounds like Myricetin (Flavone), Epioxylubimin (Sesquiterpenoids), Furocoumaric acid (Phenolic glycoside) among others. Myricetin (Flavone), one of the most important flavonols, has revealed its protective effect on HIT-T15 pancreatic beta cells from oxidative damage (Banjarnahor and Artanti 2014) due to its antioxidant properties. Therefore, the activity observed in this study could be as a result of these metabolites. In similar studies, some of these compounds were shown to be good scavengers of ROS produced by glucose toxicity in type 2 diabetes (Banjarnahor and Artanti 2014). Therefore the ability to directly scavenge the activity of ROS, should be the best way to described antioxidant activity of flavonoids. Flavonoids are able to chelate free radicals immediately by donating a hydrogen 
atom or by single-electron transfer, another possible mechanism of action of flavonoids is through the chelation of transition metal elements. Flavonoids possess chelating potential, which enabled them to chelate, or binds to metal ions in human body to prevent them being accessible for oxidation. Certain flavonoids have potential capacity to chelate trace metal ions such as $\mathrm{Fe}^{2+}$ and $\mathrm{Cu}^{2+}$ that play a vital role in oxygen metabolism and free radical formation (Banjarnahor and Artanti 2014). The anti-inflammatory, antioxidant, antimicrobial and antidiabetics properties of most of the identified metabolites from this extract were reported in different literature. Flavonoids have cardiovascular protective effect which resembles their antioxidant activity. Other studies showed cumulative evidence that strongly linked the oxidative stress to cardiovascular diseases, such as myocardial infarction, myocardial ischemia or reperfusion, and atherosclerosis as well as hypertension and heart failure (Banjarnahor and Artanti 2014).

A model on the antioxidant properties of terpenoids constituents in 2,2-diphenyl-1picrylhydrazyl (DPPH) method, was proposed by Wojtunik et al. (2014). The role of terpenoids as chemopreventive and therapeutic agent against some health conditions was reported by Thoppil et al. (2011). In similar study conducted by Zwenger and Basu (2008), the roles and future potentials of plant terpenoids was also evaluated. The therapeutic uses with special emphasis on antidiabetic potential of diterpenes, triterpenoids from Salvia macrochlamys were compared (Topçu et al., 2007; Nagarajan and Brindha 2012). Kasote et al. (2015) proved remarkable nature of polyphenolics in terms of antioxidant potential to cure many lifestyle diseases, as they contain one or many aromatic rings with hydroxyl groups. Generally, the antioxidant capacity of the phenolic is directly related with the number of free hydroxyls and conjugation of side chains with the aromatic rings. (Mohandas and Kumaraswamy 2018) Flavonoids and phenolic acids of plant phenolics, are metabolically originated from the acetate via shikimate pathways, as well as the shikimate pathway from phenylalanine or tyrosine (Mohandas and Kumaraswamy 2018). Phytochemicals of this group are excellent antioxidants in both in vitro and in vivo studies. In addition, they are proven to interplay with other natural antioxidants like ascorbate or tocopherol and to synergistically enhance their biological potentials (Mohandas and Kumaraswamy 2018).

\section{CONCLUSION}

The present study shows the potentiality of the aqueous leaf extract of C. micranthum based on the in vitro assay using DPPH and Ferric Reducing Power methods. The LCMS profile conducted identify prominent metabolites (flavonols and Terpenoids) that were reported to be good antioxidant. Therefore the activities observed from this study could be as a results of the metabolites identified. Also the extract could be used against oxidative stress related diseases and or for other pharmacological benefits.

\section{REFERENCES}

Benoit, F., Valentin, A., Pelissier, Y., Diafouka, F., Marion, C., Kone-Bamba, D., Kone, M., Mallie, M., Yapo, A., and Bastide, J. (1996). In vitro antimalarial activity of vegetal extracts used in West African traditional medicine. The American journal of tropical medicine and hygiene 54, Pp. 67-71. 
Burkhill, H. M. (1985). The Useful Plants of West Tropical Africa. 2nd ed.; Royal Botanic Gardens: Kew, Great Britain.

Eloff, J. N., Katerere, D. R., and McGaw, L. J. (2008). The biological activity and chemistry of the southern African Combretaceae. Journal of Ethnopharmacology. 119, Pp. 686-699.

Ferreira, I. C., Baptista, P., Vilas-Boas M. and Barros, L. (2007). Free radical scavenging capacity and reducing power of wild edible mushrooms from northeast Portugal: individual cap and stipe activity. Foodchem., 100, Pp.1511-1516.

Benoit, F., Valentin, A., Pelissier, Y., Diafouka, F., Marion, C., Kone-Bamba, D., Kone, M., Mallie, M., Yapo, A., and Bastide, J. (1996). In vitro antimalarial activity of vegetal extracts used in West African traditional medicine. The American Journal of Tropical Medicine and Hygiene 54, Pp. 67-71.

Burkhill, H. M. (1985). The Useful Plants of West Tropical Africa. 2nd ed.; Royal Botanic Gardens: Kew, Great Britain.

Eloff, J. N., Katerere, D. R. and McGaw, L. J. (2008). The biological activity and chemistry of the southern African Combretaceae. Journal of Ethnopharmacology, 119: 686-699.

Ferreira, I. C., Baptista, P., Vilas-Boas, M. and Barros, L. (2007). Free radical scavenging capacity and reducing power of wild edible mushrooms from northeast Portugal: individual cap and stipe activity. Foodchem., 100: 1511-1516.

Greeshma Geetha Mohandas, Murugan Kumaraswamy (2018). Antioxidant Activities of Terpenoids from Thuidium tamariscellum C. Muell.) Bosch. and Sande-Lac. a Moss Pharmacogn J ; 10(4): 645-649

Ibrahim A., Onyike Nok A.J., and Umar I.A. (2017) Combination of Gymnema sylvestre and Combretum micranthum methanol leaf extracts produced synergistic hypoglycaemic activity in alloxan diabetic mice. Saudi Journal Med. Pharm. Sci. 3(11A): Pp. 1188-1199.

Jules Yoda, Seydou Sourabié, Angèle Zoungrana (2020). Antioxidant Activity of Five Medicinal Plants Extrats Used for Management of Bacterial Diseases in Burkina Faso Advances in Analytical Chemistry 10(2): 20-25

Kasote DM, Katyare SS, Hegde MV, Bae H. (2015). Significance of Antioxidant Potential of Plants and its Relevance to Therapeutic Applications. Int J Biol Sci.; 11(8):982-91. 24. Morgan JF, Klucas R

Linderschmidt, R., Trylka, A., Goad, M., and Witschi, H., (1986). The effects of dietary butylated hydroxytoluene on liver and colon tumor development in mice. Toxicology 38, Pp. 151160.

Mary, N. K., Achuthan, C. R., Babu, B. H., and Padikkala, J. (2003). In vitro antioxidant and antithrombotic activity of Hemidesmus indicus (L) R. Br. Journal of Ethnopharmacol. 87: Pp. 187-191.

Nagarajan A, Brindha P. (2012). Diterpenes-A Review on Therapeutic uses with special emphasis on Antidiabetic Activity. J Pharma Res.;5(8):4530-40.

Olajide, O.A., Makinde, J. M., and Okpako, D.T. (2003). Evaluation of the anti-inflammatory property of the extract of Combretum micranthum G. Don (Combretaceae). Inflammopharmacology 11, Pp. 293-298.

Piovesana, A., Rodrigues, E. and Norena, C.P.Z. (2018). Composition analysis of carotenoids and phenolic compounds and antioxidant activity from Hibiscus calyces (Hibiscus sabdariffa L) by HPLC-DAD-MS/MS. Phytochemical Analysis, 1-10. 435 https://doi.org/10.1002/pca. 
Rajlakshmi, D., Banerjee, S. K., Sood, S., and Maulik, S. K. (2003). In-vitro and in-vivo antioxidant activity of different extracts of the leaves of Clerodendron colebrookianum Walp in the rat. Journal of Pharmacology. Pharmacol. 55: Pp. 1681-1686.

Shen, Q. Zhang, B., Xu, R., Wang, Y, Diang, X. and Li, P. (2010). Antioxidant activity in vitro of Selenium- contained protein from the Se-enriched. Bifodo bacterium animalis 01.Anaerobe, Pp. 380-38.

Sofna D. S. Banjarnahor, and Nina Artanti (2014). Antioxidant properties of flavonoids. Med. J. Indones 23 (4): 239-244.

Thoppil R, Bishayee A. (2011). Terpenoids as potential chemopreventive and therapeutic agents in liver cancer. World J Hepatol. ;3(9):228-49.

Topçu G, Ertas A, Kolak U, Öztürk M, Ulubelen A. (2007). Antioxidant activity tests on novel triterpenoids from Salvia macrochlamys. ARKIVOC; (7):195-208.

Udoh, I., Nworu, C., Eleazar, C., Onyemelukwe, F., and Esimone, C. (2012). Antibacterial profile of extracts of Combretum micranthum G. Don against resistant and sensitive nosocomial isolates Journal of Pharmaceutical Sciences 02 (04) 142-146.

Wojtunik, K.A., Ciesla, L. M., Waksmundzka-Hajnos, M. (2014). Model studies on the antioxidant activity of common terpenoid constituents of essential oils by means of the 2,2-diphenyl-1-picrylhydrazyl method. J Agric Food Chem., 62(37): 9088-94.

Zwenger, S. and Basu, H.K. (2008). Plant terpenoids: applications and future potentials. Reviews, 3(1):1-7. 